\title{
Cost of individual complications following coronary artery bypass grafting
}

\author{
J. Hunter Mehaffey, MD, ${ }^{\text {a }}$ Robert B. Hawkins, MD, ${ }^{a}$ Matthew Byler, MD, MBA, ${ }^{a}$ Eric J. Charles, MD, ${ }^{a}$ \\ Clifford Fonner, BA, ${ }^{\mathrm{b}}$ Irving Kron, MD, ${ }^{\mathrm{a}}$ Mohammed Quader, MD, ${ }^{\mathrm{c}}$ Alan Speir, MD, ${ }^{\mathrm{d}}$ Jeff Rich, MD, ${ }^{\mathrm{b}}$ and \\ Gorav Ailawadi, MD, ${ }^{a}$ for the Virginia Cardiac Services Quality Initiative
}

\section{ABSTRACT}

Objective: The financial implications of postoperative complications in cardiac surgery remain poorly understood. The purpose of this study was to define the cost of surgery without complications and demonstrate the incremental cost of each complication.

Methods: All patients undergoing isolated coronary artery bypass grafting (CABG) were evaluated (2006-2015) from a statewide Society of Thoracic Surgeons database collaborative $(\mathrm{N}=36,588)$. Patients were stratified by presence of postoperative complications, including major morbidities as defined by the Society of Thoracic Surgeons (ie, prolonged ventilation, renal failure, reoperation, stroke, and deep sternal wound infection). Hierarchical modeling was used to identify the independent inflation-adjusted cost of each complication while controlling for hospital variation and time.

Results: The median age was 64 years, $74.3 \%$ were men, and average predicted risk of mortality was $1.9 \%$. A total of $24,738(67.7 \%)$ patients experienced no complications at an average cost of $\$ 36,580$. Each complication independently increases the cost of care and resulted in an exponential increase in cost. After accounting for incidence and incremental costs, institutions in our collaborative have spent an estimated $\$ 59.1$ million on prolonged ventilation, $\$ 8.3$ million on renal failure, $\$ 7.6$ million on reoperation, $\$ 3.3$ million on stroke, and $\$ 256,000$ on deep sternal wound infections over the past 10 years.

Conclusions: The average cost of CABG without complication was $\$ 36,580$. Each additional major complication resulted in an exponential increase in cost. Over the past 10 years, the total cost of complications after isolated CABG was $\$ 78.6$ million, emphasizing the importance of quality improvement projects to contain costs. (J Thorac Cardiovasc Surg 2018;155:875-82)

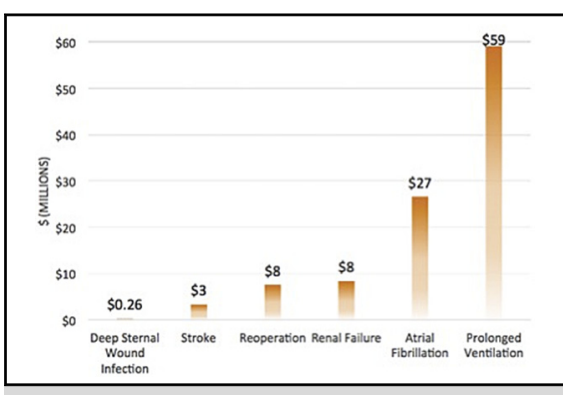

Complication-related expenditures over 10 years in the Virginia Cardiac Services Quality Initiative.

\section{Central Message}

Coronary artery bypass grafting without complications costs $\$ 36,580$ on average. Each additional major morbidity results in exponential cost increases with a 10 -year total cost of $\$ 78.6$ million

\section{Perspective}

Given the fiscal challenges expected with the bundled payment program for coronary artery bypass grafting, it is critical to understand the financial implications of postoperative complications in cardiac surgery. Understanding the costs of adverse events will help guide quality improvement projects, adapt to alternative payment models, and ultimately contain cost increases.

See Editorial Commentary page 883
Given the growing emphasis on value-driven health care, research should evaluate both sides of this equation; that is, health care-related cost and clinical outcomes. Therefore, it is critical to understand the financial implications of postoperative complications after cardiac

\footnotetext{
From athe Division of Thoracic and Cardiovascular Surgery, University of Virginia, Charlottesville, Va; ${ }^{b}$ Virginia Cardiac Services Quality Initiative, Virginia Beach, Va; ${ }^{c}$ Division of Cardiothoracic Surgery, Virginia Commonwealth University, Richmond, Va; and ${ }^{\mathrm{d}}$ INOVA Heart and Vascular Institute, Falls Church, Va.

Supported by The National Heart, Lung, and Blood Institute of the National Institutes of Health (Award Nos. T32HL007849 and UM1HL088925). The content is solely the responsibility of the authors and does not necessarily represent the official views of the National Institutes of Health.

Read at the 43rd Annual Meeting of the Western Thoracic Surgical Association, Colorado Springs, Colorado, June 21-24, 2017.
}

surgery. Complications are the major driver of cost variability and are a key target for cost reduction. ${ }^{1}$ Furthermore, it is critical to understand the cost of adverse events to estimate true costs and guide quality improvement projects. Knowing this information also allows for critical

\footnotetext{
Received for publication May 17, 2017; revisions received July 17, 2017; accepted for publication Aug 11, 2017; available ahead of print Dec 14, 2017.

Address for reprints: Gorav Ailawadi, MD, Division of Thoracic and Cardiovascula Surgery, University of Virginia, PO Box 800679, Charlottesville, VA 22908 (E-mail: ga3f@virginia.edu).

0022-5223/\$36.00

Copyright $@ 2017$ Published by Elsevier Inc. on behalf of The American Association for Thoracic Surgery

https://doi.org/10.1016/j.jtcvs.2017.08.144
} 


\section{Abbreviations and Acronyms \\ $\mathrm{CABG}=$ coronary artery bypass grafting \\ CMS $=$ Centers for Medicare and Medicaid Services \\ IPPS = Inpatient Prospective Payment System \\ LOS = length of stay \\ STS = Society of Thoracic Surgeons \\ VCSQI = Virginia Cardiac Services Quality Initiative}

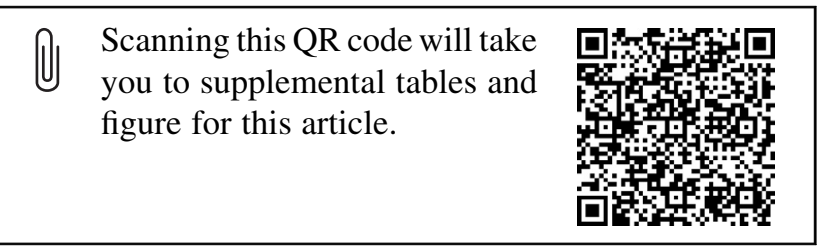

review of projects with accurate cost-effectiveness analyses. ${ }^{2,3}$ As we transition away from a fee-for-service model to a quality-based system, understanding these costs will be critical in building risk-adjusted payment models. $^{4}$

Cardiac surgery has a unique set of complications that are major drivers in the cost of surgery. ${ }^{5}$ Brown and colleagues ${ }^{6}$ found the mean cost of coronary artery bypass grafting (CABG) amongst Medicare beneficiaries to be $\$ 32,201 \pm \$ 23,059$ in 2008 . In this same study, $13.64 \%$ of the study population experienced a postoperative complication resulting in increased costs and length of stay (LOS) of $\$ 15,468$ and 5.3 days, respectively. These costs continue to increase and are outpacing estimates of medical inflation by the Centers for Medicare and Medicaid Services (CMS) Inpatient Prospective Payment System (IPPS). Another study by Speir and colleagues ${ }^{5}$ specifically demonstrated isolated postoperative atrial fibrillation to increase the cost of CABG on average $\$ 2574$, whereas prolonged ventilation, renal failure, and deep sternal wound infection had the greatest increases in total cost. Other studies have shown isolated postoperative atrial fibrillation to be associated with an additional $\$ 7000$ to $\$ 14,000$ cost increase. ${ }^{7-10}$ The large cost of complications and variation in estimates has resulted in poorly defined costs that are unable to be accurately predicted with current cost models. ${ }^{11-14}$

The purpose of this study is to analyze data from a statewide collaborative to define the cost of surgery without complications and demonstrate the incremental cost of each complication. These data may be used to identify and prioritize quality improvement initiatives that will improve patient care while providing cost-effective interventions.

\section{MATERIALS AND METHODS \\ Patient Data}

The Virginia Cardiac Services Quality Initiative (VCSQI) is composed of 18 hospitals and cardiac surgical practices in Virginia capturing 99\% of adult cardiac surgery cases in the state. Data are collected using the Society of Thoracic Surgeons (STS) clinical data entry form to capture administrative, demographic, baseline clinical, operative, and 30-day outcome data. VCSQI clinical and cost data acquisition and matching has been described previously. ${ }^{15,16}$ Charges are captured by the International Classification of Diseases, ninth revision, based revenue codes and Uniform Billing-04/92 files are matched to the STS data, with a successful matching rate of $99 \%$. These final hospital charges are then converted to estimate costs using cost-to-charge ratios submitted to CMS by each institution. Inflation estimates of the CMS IPPS were used to adjust cost to 2015 dollars to account for medical-specific inflation.

All patients undergoing isolated CABG $(\mathrm{N}=36,588)$ in the VCSQI database from January 2006 through December 2015 were evaluated. Patients were excluded for missing cost data. STS definitions were used, including postoperative atrial fibrillation and major morbidity (renal failure, reoperation, stroke, deep sternal wound infection, and prolonged ventilation). ${ }^{17}$ The data were de-identified with removal of all Health Insurance Portability and Accountability Act patient identifiers. The study was granted exemption by the University of Virginia Institutional Review Board.

\section{Statistical Analysis}

Distributions of continuous variables were not normal so they were presented as median and interquartile range except cost, which was presented as mean \pm standard deviation to more fully account for costs incurred. Categorical data were summarized as number and corresponding proportion. Nonparametric tests were used to compare categorical and continuous data for each of the preoperative variables stratified by incidence of an STS major morbidity. Additionally, mean costs were calculated with an incremental additive cost from surgery without complications. To ascertain the cost of each individual complication, hierarchical multivariate linear regression was used to estimate the contribution of each event to the total hospital cost. This was also performed for total hospital LOS and intensive care unit LOS. Each inhospital postoperative event occurring with a frequency of at least $5 \%$ was included in the model as well as all STS major morbidities. Models included all complications of interest, and were adjusted for surgery without complications, hospital and year. Variation of inflation factors was used to assess collinearity of variables within the model. All statistical analyses were performed using SAS version 9.4 (SAS Institute Inc, Cary, NC). Statistical significance was set at $\alpha<0.05$. Incremental cost of major morbidities and change in cost over time were modeled in Prism 7 (GraphPad Software Inc, La Jolla, Calif) with calculation of goodness of fit.

\section{RESULTS \\ Baseline Characteristics and Outcomes}

Over the past decade, 36,588 patients underwent isolated CABG at the 18 centers in the Commonwealth of Virginia. The average age was 64 years, $74.3 \%$ were men, and mean STS predicted risk of mortality was $1.9 \%$ at 30 days. Patients experiencing STS major morbidities postoperatively were older, with significantly higher rates of medical comorbidities and underwent longer operations (Table 1). Additionally, over the past 10 years patients undergoing isolated CABG have had increasing risk profiles for both STS Predicted Risk of Mortality (slope $[\mathrm{m}]=0.103 ; P=.003$ ) and STS Predicted Risk of Morbidity and Mortality (slope $[\mathrm{m}]=0.330$; $P<.0001)$ as demonstrated in Figure E1. Despite this 
TABLE 1. Population characteristics

\begin{tabular}{|c|c|c|c|}
\hline Characteristic & $\begin{array}{c}\text { No major morbidity } \\
\quad(n=31,815)\end{array}$ & $\begin{array}{l}\text { Major morbidity } \\
\quad(n=4773)\end{array}$ & $P$ value \\
\hline \multicolumn{4}{|l|}{ Preoperative } \\
\hline Age (y) & $64 \pm 14$ & $66 \pm 15$ & $<.0001$ \\
\hline Sex (male) & $23,574(74.1)$ & $3575(74.8)$ & $<.0001$ \\
\hline Body mass index & $28.7 \pm 6.9$ & $29.4 \pm 8.0$ & $<.0001$ \\
\hline Diabetes & $13,312(41.8)$ & $2382(49.9)$ & $<.0001$ \\
\hline Hypertension & $26,811(84.3)$ & $4222(88.5)$ & $<.0001$ \\
\hline End-stage renal disease & $680(2.8)$ & $246(6.8)$ & $<.0001$ \\
\hline Ejection fraction $(\%)$ & $55 \pm 15$ & $50 \pm 25$ & $<.0001$ \\
\hline Number of diseased vessels & & & $<.0001$ \\
\hline 1 & $1373(4.3)$ & $134(2.8)$ & \\
\hline 2 & $6065(19.1)$ & $721(15.1)$ & \\
\hline$\geq 3$ & $24,295(76.5)$ & $3893(81.8)$ & \\
\hline Urgent status & $18,156(57.1)$ & $2922(61.2)$ & $<.0001$ \\
\hline Hematocrit & $39 \pm 6$ & $37 \pm 8$ & $<.0001$ \\
\hline $\begin{array}{l}\text { Society of Thoracic Surgeons Predicted Risk of Morbidity and Mortality } \\
\text { score }(\%)\end{array}$ & $10.2 \pm 8.4$ & $17.5 \pm 18.5$ & $<.0001$ \\
\hline Society of Thoracic Surgeons Predicted Risk of Mortality score (\%) & $0.9 \pm 1.2$ & $1.9 \pm 3.3$ & $<.0001$ \\
\hline \multicolumn{4}{|l|}{ Operative } \\
\hline Cardiopulmonary bypass used & $29,137(91.6)$ & $4460(93.4)$ & $<.0001$ \\
\hline Cardiopulmonary bypass time (min) & $90 \pm 42$ & $96.5 \pm 47$ & $<.0001$ \\
\hline Both internal thoracic arteries used & $979(3.1)$ & $83(1.7)$ & $<.0001$ \\
\hline Left internal thoracic artery used & $29,013(91.3)$ & $4174(87.5)$ & $<.0001$ \\
\hline No internal thoracic artery used & $1629(5.1)$ & $494(10.4)$ & $<.0001$ \\
\hline
\end{tabular}

Values are presented as median (interquartile range).

increasing risk, outcomes in this population were better than predicted with observed to expected ratios for major morbidity and mortality below 1.0 (Table 1). Of note, the rate of postoperative atrial fibrillation was $18.4 \%$ in this population (Table 2).

\section{Influence of Major Morbidities}

Incremental additive cost of each additional complication was calculated using surgery without complications as the baseline (Table 3). The cost of CABG without complications in this population was $\$ 36,580 \pm \$ 14,633$. Mean cost for isolated atrial fibrillation includes patients with postoperative atrial fibrillation as their only postoperative

TABLE 2. Outcomes $(\mathrm{N}=\mathbf{3 6 , 5 8 8})$

\begin{tabular}{lc}
\hline \multicolumn{1}{c}{ Postoperative } & Result \\
\hline Atrial fibrillation & $6745(18.4)$ \\
Prolonged ventilation & $3281(9.0)$ \\
Reoperation & $1189(3.3)$ \\
Renal failure & $963(2.6)$ \\
Stroke & $435(1.2)$ \\
Deep sternal wound infection & $27(0.1)$ \\
Any major morbidity & $4628(12.7)$ \\
30-d mortality & $230(0.6)$ \\
\hline
\end{tabular}

Values are presented as $\mathrm{n}(\%)$. occurrence. The zero major morbidities group includes patients with in-hospital occurrences but no STS major morbidities. Each additional major morbidity experienced by patients incurred increase in total hospital cost (Figure 1). This curve was compared for goodness of fit between an exponential growth equation $\left(R^{2}=0.999\right)$ and a linear equation $\left(R^{2}=0.942\right)$ demonstrating each additional major morbidity is not additive, but instead exponentially increases cost. The exponential model demonstrated good fit with $\kappa=0.548$ and a doubling every additional 1.2 major morbidities.

\section{Rising Cost of Complications}

Despite medical inflation adjustment using the CMS IPPS, cost of CABG has increased over the past decade $(P<.0001)$. When stratified by patients with (slope, $\$ 3984 \pm \$ 709$ per year) and without (slope, $\$ 1360 \pm \$ 127$ per year) a STS major morbidity, we demonstrate the rate of increase in yearly mean cost is significantly higher in the group with complications (Figure 2) $(P=.002)$. The linear regression for each model performed adequately (no major morbidity $R^{2}=0.94$ and major morbidity $R^{2}=0.80$ ).

\section{Incremental Cost of Complications}

Results of the hierarchal model define costs for each complication (Table 3). The model performed well, with 
TABLE 3. Incremental cost of major morbidities after coronary artery bypass surgery

\begin{tabular}{lccr}
\hline \multicolumn{1}{c}{ Population } & Patients (n [\%]) & Mean \pm standard deviation & Difference \\
\hline Surgery without any complication & $24,738(67.7)$ & $36,580 \pm 14,633$ & - \\
Isolated postoperative atrial fibrillation & $5345(14.6)$ & $42,363 \pm 18,354$ & +5783 \\
0 STS major morbidities & $31,960(87.2)$ & $38,345 \pm 16,412$ & +1675 \\
1 STS major morbidity & $3584(9.8)$ & $64,542 \pm 39,456$ & $+27,872$ \\
2 STS major morbidities & $839(2.3)$ & $111,239 \pm 76,177$ & $+74,569$ \\
3+ STS major morbidities & $205(0.6)$ & $194,043 \pm 127,518$ & $+157,463$ \\
\hline
\end{tabular}

STS, Society of Thoracic Surgeons.

an $R^{2}$ value of 0.724 (Table 4). Based on these estimates and the incidence rate of each major morbidity, the overall costs of each complication over the past 10 years in the Commonwealth of Virginia were calculated (Figure 3). Cardiac surgery centers in the VCSQI collaborative have spent more than $\$ 78.6$ million on complications with prolonged ventilation being the highest at $\$ 59.1$ million due to the high incidence. To further evaluate the influence of complications on resource utilization, we demonstrate that each complication has a significant and predictable effect on hospital LOS (Table E1) $\left(R^{2}=0.410\right)$. Likewise, we see a similar effect for intensive care unit LOS (Table E2) $\left(R^{2}=0.346\right)$.

\section{DISCUSSION}

The cost of CABG is highly variable and continues to rise, outpacing medical inflation. These increases are significantly influenced by postoperative complications, the cost of which is growing at an even more rapid rate. The current cost of CABG without complications is $\$ 36,580$ in 2015 dollars. The cost of each major morbidity accrued is not additive, but instead found to increase total cost exponentially.

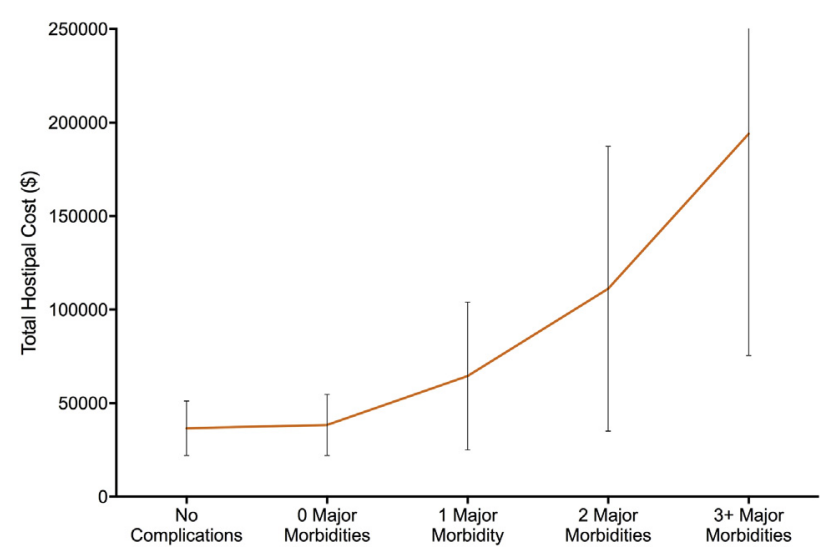

FIGURE 1. Incremental cost of major morbidities after coronary artery bypass surgery. Each additional major morbidity experienced by patients incurs a major increase in total hospital cost. This curve was compared for goodness of fit between an exponential growth equation $\left(R^{2}=0.999\right)$ and a linear equation $\left(R^{2}=0.942\right)$. The exponential model demonstrated good fit with $\kappa=0.548$ and a doubling with every additional 1.2 major morbidities.
This study also calculates the independent cost of each common complication after cardiac surgery. Finally, when considering the incidence of each event, we demonstrate that prolonged ventilation had the highest cumulative cost over the past decade in the Commonwealth of Virginia.

The estimates for complication-free CABG surgery continue to rise, over and above medical inflation, which is adjusted for using CMS IPPS estimates. Kilic and colleagues ${ }^{1}$ in 2014 reported that complications after cardiac surgery are the primary driver of cost variation. Our data further support this claim. We demonstrate a significantly higher rate of increase in patients with STS major morbidities compared with costs in patients not experiencing a STS major morbidity after surgery. The increasing risk profiles of patients undergoing $\mathrm{CABG}$ continue to make case more challenging with fewer low risk operations. ${ }^{18,19}$ Given the complexity of cases and the growing burden of comorbid disease, these complications will become more difficult to prevent despite being a driving force behind expanding costs. Therefore, understanding these expenses and being able to accurately predict them will be critical

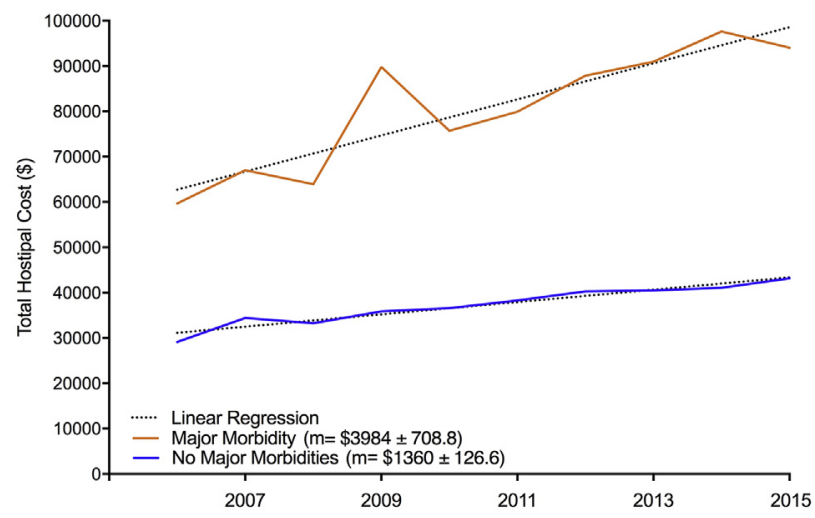

FIGURE 2. Rate of cost increase over time. Despite medical inflation adjustment using the Center for Medicare an Medicaid Services Inpatient Prospective Payment System, cost of coronary artery bypass grafting has continued to increase over the past decade $(P<.0001)$. Patients were stratified as having a Society of Thoracic Surgeons major morbidity (orange line, slope $=3984 \pm 709$ ) or not (blue line, slope $=1360 \pm 127$ ) $(P=.002)$. The linear regression for each model performed adequately (no major morbidity $R^{2}=0.94$ and major morbidity $R^{2}=0.80$ ). 
TABLE 4. Independent cost effects of complications after coronary artery bypass grafting

\begin{tabular}{lccc}
\hline \multicolumn{1}{c}{ Complication } & $\begin{array}{c}\text { Estimate } \\
\mathbf{( \$ )}\end{array}$ & $\begin{array}{c}\mathbf{9 5} \% \text { Confidence } \\
\text { interval }\end{array}$ & $\boldsymbol{P}$ value \\
\hline Blood transfusion & +6763 & $6195-7331$ & $<.0001$ \\
$\begin{array}{l}\text { Postoperative atrial } \\
\text { fibrillation }\end{array}$ & +5673 & $4760-6586$ & $<.0001$ \\
\hline $\begin{array}{l}\text { Prolonged } \\
\quad \text { ventilation }(>24 \mathrm{~h})\end{array}$ & $+33,840$ & $32,826-34,855$ & $<.0001$ \\
Reoperation & $+35,239$ & $33,772-36,706$ & $<.0001$ \\
\hline Stroke & $+18,423$ & $16,147-20,699$ & $<.0001$ \\
Renal failure & $+33,847$ & $32,269-35,424$ & $<.0001$ \\
\hline Deep sternal wound infection & $+19,835$ & $10,937-28,733$ & $<.0001$ \\
\hline Operative mortality & $+13,474$ & $10,403-16,545$ & $<.0001$ \\
\hline
\end{tabular}

in developing payment models to appropriately reimburse hospital systems providing care to these complex patients with high risk of complications.

Prior work has identified the incremental costs associated with certain complications. ${ }^{5}$ Our work builds on this by examining the interaction between complications, which suggests that accumulation of multiple major morbidities increase cost exponentially. This highlights the difficultly in predicting costs. Patients who develop a single complication are at increased risk for a subsequent complication, and these additional costs should be modeled on a logarithmic order. Although the STS risk predictor tool does an outstanding job of predicting clinical outcomes, these models do not accurately risk adjust for cost. ${ }^{20,21}$ Our group has recently demonstrated that cost models do not adequately account for patients experiencing complications after surgery, as modeled in the CABG bundled payments using DRG definitions. ${ }^{14}$ Therefore, it

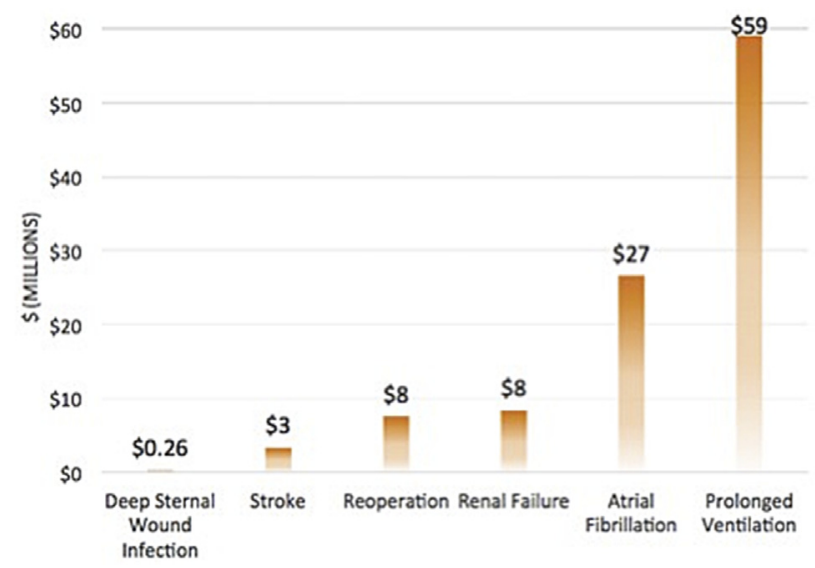

FIGURE 3. Complication-related expenditures over 10 years in Virginia. Cardiac surgery centers in the Virginia Cardiac Services Quality Initiative collaborative have spent more than $\$ 78.6$ million on complications with prolonged ventilation being the highest at $\$ 59.1$ million due to the high incidence. is critical for large datasets like the VCSQI to regularly update these estimates for cost modeling.

In the era of quality improvement, cardiac surgery programs are bombarded with various protocols and initiatives to improve the overall care of patients. However, using the value framework, these initiatives should be evaluated on the basis of cost-effectiveness using the specific cost estimates that have been derived via this study. We have demonstrated that prolonged ventilation incurs the highest expenditures in Virginia. Given the high incidence, this equates to a price tag of $\$ 59.1$ million attributable over the past decade. Given this financial burden, our quality collaborative has focused on initiatives that will reduce this common complication. Similarly, blood transfusions have a significant financial burden given the high incidence of administration. Our group has recently demonstrated the use of rotational thromboelastometry to decrease blood transfusion. ${ }^{22}$ Additionally, several institutions have moved to prophylactic amiodarone protocols to reduce the incidence of postoperative atrial fibrillation. With the use of cost estimates derived from large collaborative datasets, these quality improvement projects can be rigorously and quantitatively evaluated using cost-effectiveness methods to ensure value is provided.

This study is limited by its retrospective nature with inherent selection bias and precludes demonstration of causality. Furthermore, the VCSQI uses cost-to-charge ratios reported to CMS each year to estimate cost. Hierarchal modeling was used to adjust for hospital-level variation as well as yearly variation during the study period; however, we are unable to adjust for unknown factors that may contribute bias to the study.

\section{CONCLUSIONS}

The increasing cost of CABG is outpacing medicalspecific inflation and is driven primarily by postoperative complications. Whereas each complication has incremental costs directly attributable to its treatment, each additional complication increases total hospital cost exponentially. The significant variations in total hospital costs make payment models susceptible to significant error. Accurate estimates for costs attributable to specific complications will be critical as we move toward value-based health care models.

\section{Conflict of Interest Statement}

A.S. is a consultant on the Medtronic Cardiac Surgery Advisory Board and G.A. is a consultant for Abbott, Edwards, and Medtronic, and has been a speaker for Atricure within the past 3 years but not in the past year. All other authors have nothing to disclose with regard to commercial support.

\section{References}

1. Kilic A, Shah AS, Conte JV, Mandal K, Baumgartner W, Cameron DE, et al. Understanding variability in hospital-specific costs of coronary artery bypass grafting represents an opportunity for standardizing care and improving resource use. J Thorac Cardiovasc Surg. 2014;147:109-15. 
2. Vieira RD, Hueb W, Hlatky M, Favarato D, Rezende PC, Garzillo CL, et al. Costeffectiveness analysis for surgical, angioplasty, or medical therapeutics for coronary artery disease: 5-year follow-up of medicine, angioplasty, or surgery study (MASS) II trial. Circulation. 2012;126:S145-50.

3. Ishak KJ, Stolar M, Hu MY, Alvarez P, Wang Y, Getsios D, et al. Accounting for the relationship between per diem cost and LOS when estimating hospitalization costs. BMC Health Serv Res. 2012;12:439.

4. Eisenstein EL, Sun JL, Anstrom KJ, DeLong ER, Szczech LA, Mark DB. Assessing the economic attractiveness of coronary artery revascularization in chronic kidney disease patients. J Med Syst. 2009;33:287-97.

5. Speir AM, Kasirajan V, Barnett SD, Fonner E Jr. Additive costs of postoperative complications for isolated coronary artery bypass grafting patients in Virginia. Ann Thorac Surg. 2009;88:40-5; discussion 45-6.

6. Brown PP, Kugelmass AD, Cohen DJ, Reynolds MR, Culler SD, Dee AD, et al. The frequency and cost of complications associated with coronary artery bypass grafting surgery: results from the United States Medicare program. Ann Thorac Surg. 2008;85:1980-6.

7. Aranki SF, Shaw DP, Adams DH, Rizzo RJ, Couper GS, VanderVillet M, et al. Predictors of atrial fibrillation after coronary artery surgery. Current trends and impact on hospital resources. Circulation. 1996;94:390-7.

8. Hravnak M, Hoffman LA, Saul MI, Zullo TG, Whitman GR. Resource utilization related to atrial fibrillation after coronary artery bypass grafting. American J Crit Care. 2002;11:228-38.

9. Almassi GH, Wagner TH, Carr B, Hattler B, Collins JF, Quin JA, et al. Postoperative atrial fibrillation impacts on costs and one-year clinical outcomes: the Veterans Affairs Randomized On/Off Bypass Trial. Ann Thorac Surg. 2015;99: 109-14.

10. LaPar DJ, Speir AM, Crosby IK, Fonner E Jr, Brown M, Rich JB, et al. Postoperative atrial fibrillation significantly increases mortality, hospital readmission, and hospital costs. Ann Thorac Surg. 2014;98:527-33; discussion 533.

11. Herzlinger RE, Schleicher SM, Mullangi S. Health care delivery innovations that integrate care? Yes!: But integrating what? JAMA. 2016;315:1109-10.

12. Scally CP, Thumma JR, Birkmeyer JD, Dimick JB. Impact of surgical quality improvement on payments in Medicare patients. Ann Surg. 2015;262:249-52.

13. Osborne NH, Nicholas LH, Ryan AM, Thumma JR, Dimick JB. Association of hospital participation in a quality reporting program with surgical outcomes and expenditures for Medicare beneficiaries. JAMA. 2015;313:496-504.

14. Hawkins RB, Mehaffey JH, Yount KW, Yarboro LT, Fonner C, Kron IL, et al. Coronary artery bypass grafting bundled payment proposal will have significant financial impact on hospitals. J Thorac Cardiovasc Surg. 2018 [in review].

15. Ailawadi G, LaPar DJ, Speir AM, Ghanta RK, Yarboro LT, Crosby IK, et al. Contemporary costs associated with transcatheter aortic valve replacement: a propensity-matched cost analysis. Ann Thorac Surg. 2016;101:154-60; discussion 160 .

16. Osnabrugge RL, Speir AM, Head SJ, Fonner CE, Fonner E Jr, Ailawadi G, et al. Costs for surgical aortic valve replacement according to preoperative risk categories. Ann Thorac Surg. 2013;96:500-6.

17. Society of Thoracic Surgeons. Adult cardiac surgery data collection. Available at: http://www.sts.org/sts-national-database/database-managers/adult-cardiac-surgerydatabase/data-collection - data2017. Accessed September 12, 2016.

18. Deb S, Wijeysundera HC, Ko DT, Tsubota H, Hill S, Fremes SE. Coronary artery bypass graft surgery vs percutaneous interventions in coronary revascularization: a systematic review. JAMA. 2013;310:2086-95.

19. Ngaage DL, Griffin S, Guvendik L, Cowen ME, Cale AR. Changing operative characteristics of patients undergoing operations for coronary artery disease: impact on early outcomes. Ann Thorac Surg. 2008;86:1424-30.

20. LaPar DJ, Stukenborg GJ, Guyer RA, Stone ML, Bhamidipati CM, Lau CL, et al. Primary payer status is associated with mortality and resource utilization for coronary artery bypass grafting. Circulation. 2012;126:S132-9.

21. Yount KW, Isbell JM, Lichtendahl C, Dietch Z, Ailawadi G, Kron IL, et al. Bundled payments in cardiac surgery: is risk adjustment sufficient to make it feasible? Ann Thorac Surg. 2015;100:1646-52; discussion 1652.

22. Mehaffey JH, Schubert SA, Gelvin MG, Charles EJ, Hawkins RB, Johnston LE, et al. A new intraoperative protocol for reducing perioperative transfusions in cardiac surgery. Ann Thorac Surg. 2017;104:176-81.

Key Words: cardiac surgery, cost, complications, incremental cost
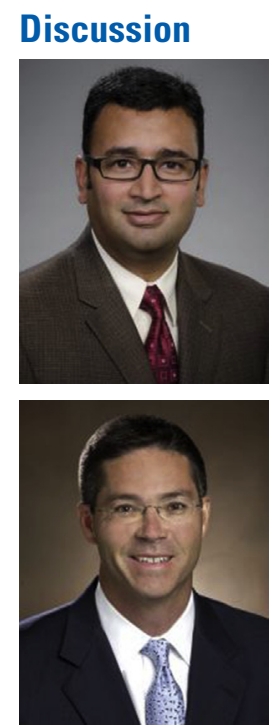

Moderators: Nahush A. Mokadam

Moderator. Good morning everybody.We'll start off this session with paper number 4, "Cost of Individual Complications Following Coronary Artery Bypass Grafting," presented by Dr Mehaffey from UVA, and colleagues.

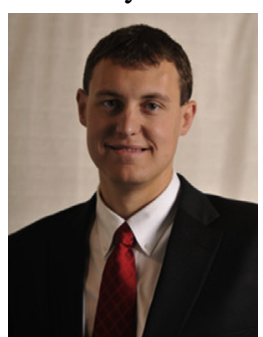

James Mehaffey. Thank you for the opportunity to present our work. We have no disclosures. So, it's critical to understand the financial implications of postoperative complications in cardiac surgery. It's important to be able to evaluate our quality improvement initiatives, it's important to be able to define value in healthcare, and it will provide a framework for future bundled payment programs. The purpose of this study was to define the cost of coronary artery bypass grafting with no complications, and demonstrate individual and incremental cost of complications in a statewide data set. We hypothesized that complications after CABG are associated with specific and definable costs and each additional complication results in exponential increase in cost. We used the Virginia Cardiac Services Quality Initiative, which is a consortium of the 19 cardiac institutions in the state of Virginia who pool their society of thoracic surgeons' data. Additionally, the database includes UB-04 billing data and institution-specific cost:charge ratio, which allows a calculation of estimated true cost. We evaluated all patients undergoing isolated CABG over a ten-year period from 2006 through 2015 . This was a total of 36,588 cases. We evaluated each of the Society of Thoracic Surgery major morbidities defined as prolonged ventilation greater than 24 hours, reoperation, renal failure, stroke, and deep sternal wound infection. Additionally, we looked at minor complications, including postoperative atrial fibrillation as well as blood transfusion. We then used hierarchal linear regression 
modeling with complications as covariates and accounted for random effects of institution level variability and year.

So here was our standard isolated CABG population, 36,000 patients, predicted risk of mortality just under $2 \%$, a pretty standard population. When we evaluated the outcomes, we see that patients in our collaborative did quite well with postoperative atrial fibrillation rates of $18.4 \%$ and 30 -day mortality less than $1 \%$. When we look at observed:expected ratios for both major morbidity or mortality as well as 30-day mortality, we see that the collaborative as a whole performed better than expected and had an O:E ratio less than 1.0. We next evaluated the inflation-adjusted costs of coronary artery bypass for this patient population. As you can see here, patients with no complications, meaning they do not experience an STS major morbidity or any of the minor complications have an average total hospital cost of $\$ 36,500$. Now the subset of patients who experienced a minor complication but did not experience a major morbidity had an average increase of about \$2000 in their total hospital cost. However, the population of patients experiencing one or more major morbidities demonstrated a significant and dramatic increase in total hospital costs, and this demonstrated an exponential relationship as demonstrated here in the figure with each additional major morbidity. We next looked at the cost of coronary artery bypass over time, and for this again we used inflation-adjusted cost, adjusted by the Center for Medicare and Medicaid Services, medical specific inflation adjustment, so the blue line at the bottom demonstrates the total hospital cost of all patients undergoing $\mathrm{CABG}$ who did not experience one of the STS major morbidities.

As you can see here, despite adjustment for inflation, the cost increased by about $\$ 1300$ a year. However, in the orange line above, this demonstrates the average hospital cost of the patients experiencing one or more major morbidities, and you can see here once again after adjustment for inflation, these patients had a yearly increase of almost $\$ 4000$ in total hospital costs. We next used hierarchal linear regression to identify attributable cost for each of these major morbidities as well as minor complications to the total hospital cost of the patient. As you can see here in our collaborative, some of the most costly morbidities included reoperation, renal failure, and prolonged ventilation. However, even the minor complications contributed significantly to the model, both blood transfusion and postoperative AFib contributing about $\$ 6000$ in total hospital cost to patients experiencing this complication. However, this doesn't tell the whole story, because while we can identify the costs associated with each individual complication, we must look at this in the framework of considering the incidence of that complication. So next we looked at the total tenyear cost within the collaborative of each of these major morbidities. We did this by multiplying the incidence of the complication by the incremental cost of that complication, prolonged ventilation and atrial fibrillation were the most costly complications. Limitations of this study include its retrospective nature and the inability to evaluate variables that are not included in the database. In conclusion, additional complications increase total hospital costs and the cost of CABG is outpacing medical specific inflation, and is driven primarily by postoperative complications. Furthermore, specific complications have identifiable cost that may be used for risk adjustment and reimbursement models. However, total expenditure is based on cost and incidence of complication, therefore accurate cost estimation should be used to guide research and quality improvement allocation.

Participant. Congratulations, so really nice and [tape blank]. I have a few questions, I have 4 questions for you. First related to methodology ___ [tape blank] I noted that the ___ [tape blank] for all the complications [tape blank] but you know, I think comorbidities [tape blank] may affect the population ___ [tape blank] for example patients with diabetes, who goes back to ___ [tape blank].

Participant. What about ... did you consider at all including comorbid variables model that might help us [tape blank] in your

James Mehaffey. Yeah I think that's an excellent question and what you're hitting on is essentially what Medicare is doing right now, their goal is to build a model to predicts how much a CABG patient is going to cost to take care of. The problem with this goal is that while predicting average cost is possible with statistical modeling, there are significant cost outliers. The proposed bundled payments shifts this financial risk to the institutions. The other problem with models is they are based on preoperative characteristics and I think the answer is not just comorbidities, it's socioeconomic factors, payer status, it's how far they are traveling for their operation and where they come from and what kind of care infrastructure they have when they go back there.

Participant. Certainly, I 100\% agree that it's part of a model that predicts what the cost will ___ [tape blank] and I think that is one of the things that our outcomes group is working on and we definitely don't have the answer to that. This study is certainly not directly trying to build a cost model for reimbursement, but to your point, [tape blank] \% will include patient level medical factors, as well as patient level socioeconomic crisis of our generation [tape blank].

Participant. _ [tape blank] \% of the [tape blank] blank] differences in the conversation [tape blank].

James Mehaffey. Yes, that's an excellent question and the subset analysis has not __ [tape blank] relatively low rates of ___ [tape blank] very early study period. I think adjustment for ___ [tape blank] look at further patient outcome ___ [tape blank]. 
Participant. One other thing in your slide [tape blank] didn't end up in your overall analysis. I wonder what the overall cost of the single blood transfusion [tape blank] that's one of the things that

[tape blank].

James Mehaffey. Certainly, I think that's a really good question, and I think that it's actually two-fold, it's not just how much the bag of red blood cells costs, and what this analysis got at is for a patient who got a blood transfusion how does that effect the cost overall. Clearly the bag of blood doesn't cost $\$ 6,000$ it's more looking at the patient who's getting a blood transfusion has so many other issues going on and we identified that cost. You look back in the last decade and institutions in our collaborative spend over $\$ 60$ million on prolonged ventilation and $\$ 30$ million on Afib and those are the center of our quality improvement initiatives. You have to find and identify one thing that you're going to tackle first and one way to decide if what has the largest financial burden.

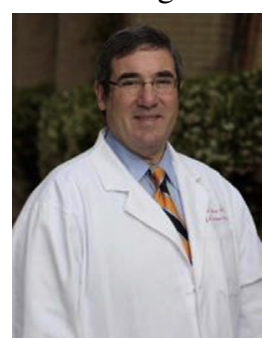

Richard Shemin. This is very useful data from all the cardiac surgery centers in Virginia. You have quantified the cost of complications after CABG surgery. How will you specifically use the data for bundled negotiation?

James Mehaffey. Certainly and I'm actually going to tackle your second question first. Postoperative AFib as you mentioned has been one of our low performance outliers and just from the beginning of the decade that we looked at, we had rates over $25 \%$ and in the last couple of years it's been low, 15 or $16 \%$. I think we are moving the needle on this bar, and making a meaningful impact. Your first question...

Richard Shemin. How much institutional variability do you measure among the participating centers?

James Mehaffey. Yes, variability is unbelievable and I think that's one of the biggest issues with creating a cost model. One of our recent studies show that if you implemented the proposed CABG bundle, a difference in how that would have done if the last 5 years were the proposed next 5 years is terrifying. There are several hospitals in our collaborative that would owe Medicare a couple million dollars just because of the cost of variability. With the shifting of financial risks to the hospitals this variability makes me wonder how some institutions can survive.

Richard Shemin. My final quick comment returns to the complexity of these efforts to capture patient viability, best practice and cost containment so the result of bundled methodology does not bankrupt our hospitals.

James Mehaffey. Certainly, and I think that's an excellent question and something Dr Rich is actively working to get all payer charges for patients post acute care. 


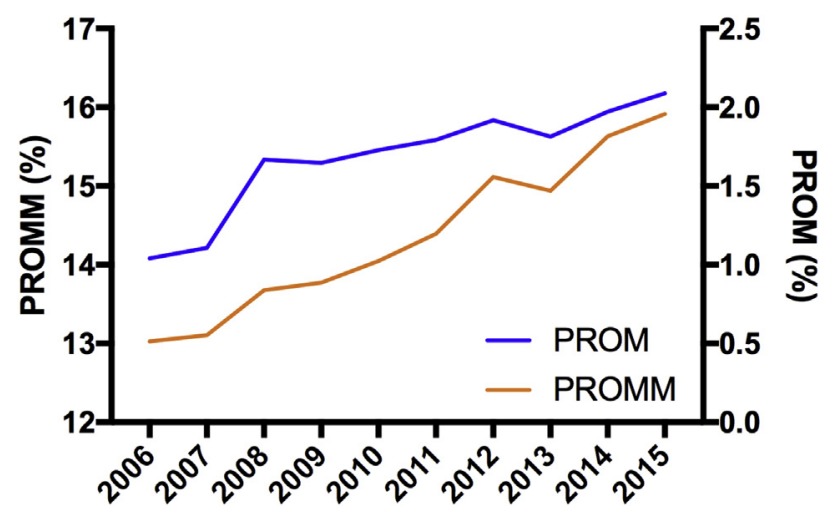

FIGURE E1. Risk profiles over 10 years in Virginia. Yearly average Society of Thoracic Surgeons Predicted Risk of Mortality (PROM) and Society of Thoracic Surgeons Predicted Risk of Mortality and Morbidity $(P R O M M)$ scores for all cardiac surgery centers in the Virginia Cardiac Services Quality Initiative collaborative are increasing yearly over the past decade.
TABLE E2. Independent intensive care unit length of stay effects of complications after coronary artery bypass grafting

\begin{tabular}{lccr}
\hline \multicolumn{1}{c}{ Complication } & \multicolumn{3}{c}{ 95\% Confidence } \\
\hline Blood transfusion & 24.73 & $23.63-25.84$ & $<.0001$ \\
$\begin{array}{l}\text { Postoperative atrial } \\
\quad \text { fibrillation }\end{array}$ & 33.73 & $31.94-35.53$ & $<.0001$ \\
$\begin{array}{l}\text { Prolonged } \\
\quad \text { ventilation }(>24 \text { h) }\end{array}$ & 152.32 & $150.33-154.31$ & $<.0001$ \\
Reoperation & 105.28 & $102.39-108.16$ & $<.0001$ \\
Stroke & 102.72 & $98.22-107.22$ & $<.0001$ \\
Renal failure & 127.90 & $124.80-131.00$ & $<.0001$ \\
\hline Deep sternal wound infection & 19.61 & $2.30-36.93$ & .2572 \\
\hline Operative mortality & 43.52 & $37.43-49.61$ & $<.0001$ \\
\hline
\end{tabular}

TABLE E1. Independent length of stay effects of complications after coronary artery bypass grafting

\begin{tabular}{lccc}
\hline \multicolumn{1}{c}{ Complication } & \multicolumn{3}{c}{$95 \%$ Confidence } \\
\hline Blood transfusion & 1.76 & $1.71-1.82$ & $<.0001$ \\
$\begin{array}{l}\text { Postoperative atrial } \\
\text { fibrillation }\end{array}$ & 1.42 & $1.33-1.51$ & $<.0001$ \\
$\begin{array}{l}\text { Prolonged } \\
\quad \text { centilation }(>24 \mathrm{~h})\end{array}$ & 6.86 & $6.76-6.97$ & $<.0001$ \\
Reoperation & 7.20 & $7.05-7.35$ & $<.0001$ \\
\hline Stroke & 5.95 & $5.72-6.18$ & $<.0001$ \\
Renal failure & 7.74 & $7.58-7.90$ & $<.0001$ \\
\hline Deep sternal wound infection & 2.96 & $2.06-3.86$ & .001 \\
\hline Operative mortality & 2.76 & $2.4-3.07$ & $<.0001$ \\
\hline
\end{tabular}

